\title{
PROGRAMAS DE ATENÇÃO ÀS CRIANÇAS E AOS ADOLESCENTES EM SITUAÇAO DE RUA: PERCEPÇÕES DE SEUS COORDENADORES*
}

\section{ASSISTANCE PROGRAMS FOR CHILDREN AND ADOLESCENT'S \\ IN STREET SITUATION: SOME PERCEPTIONS OF THEIR CO-ORDINATORS}

\author{
Marcelo Medeiros 1 \\ Maria das Graças Carvalho Ferriani ${ }^{2}$
}

MEDEIROS, M., FERRIANI, M. G. C. Programas de Atenção às Crianças e aos Adolescentes em Situação de Rua: Percepções de seus Coordenadores. Rev. Bras. Cresc. Desenv. Hum., São Paulo, 5(1/2), 1995

Resumo: O propósito deste estudo é conhecer e compreender as percepções dos atares sociais que planejarn e/ou coordenam programas assistenciais para crianças e adolescentes que vivem em situação de rua em uma cidade do interior paulista. Como objetivo buscamos: identificar os programas desenvolvidos na cidade com crianças e adolescentes em situação de rua; conhecer a compreensão dos coordenadores/ atares sociais sobre estas crianças e adolescentes, identificar o significado que estes atares sociais atribuíam aos programas desenvolvidos. Orientamos o desenvolvimento do estudo através de um referencial teórico-metodológico qualitativo, que pretendeu compreender o tema de modo particular, sem generalizá-lo. O material para análise foi coletado através da observação livre, entrevista semi-estruturada e documentos oficiais. Os dados oriundos deste processo foram analisados à luz da proposta da hermenêutica-dialética elaborada por MINAYO (1993). A análise realizada permitiu-nos conhecer alguns aspectos sobre a compreensão dos atares sociais a respeito das crianças e adolescentes em situação de rua bem como o que significavam para eles os programas assistenciais desenvolvidos para este grupo em Ribeirão Preto (SP).

Palavras-chave: criança, adolescente, abandono

Summary: The purpose of this study is to know and understand the perceptions of the social participant who plan and/or coordinate assistance programs for chidren and adolescents that live in street situation ir a city in the State of Sao Paulo. Our aim was to identify the programs developed in the city, and also, tc identify the programs coordinators' understanding of children and adolescents in street situation, as wel as the meaning of these programs to these social participants. The development of this study was guides by a qualitative theoretical reference, that intends to understand the theme in a particular way, withou generalizations. The data were collected through free observation, semi-structured interviews and analyst! of official documents. The data have been analysed in accordance with MINAYO’s (1993) proposal Thus, it was possible for us to know the social participants’ understanding of children and adolescents it street situation as well as what these assistance programs, developed in Ribeirao Preto (SP), mean tc them.

Key-words: children, adolescent, abandonment.

* Este artigo é baseado na dissertação de Mestrado do primeiro autor, apresentada à Escola de Enfermagem de Ribeirão Preto da Universidade de São Paulo Programa de Pós-Graduação nível Mestrado do Departamento de Enfermagem Geral e Especializada, na área de concentração de Enfermagem Fundamental, no ano de 1995 intitulada "Percepções dos valores sociais que coordenam programas de atenção às crianças e aos adolescentes em situação de rua no município de Ribeirão Preto (SP)”. A pesquisa contou com subvenção parcial do PICD - CAPES.

1 Prof. Assistente da Faculdade de Enfermagem e Nutrição da Universidade Federal de Goiás; Aluno do Programa Interunidades de Doutorado em Enfermagem da Escola de Enfermagem de Ribeirão Preto da Universidade de São Paulo. End.: Rua 227, s/n Qd 68, CEP 70605-080, Goiânia, Goiás. Fone (062) 261-6611, Fax (062) 202-1033.

2 Profa. Associada do Departamento de Enfermagem Materno Infantil e Saúde Pública da Escola de Enfermagem de Ribeirão Preto da Universidade de São Paulo. End.:Av. Bandeirantes, 390O, Campus USP, CEP 14040-902, Ribeirão Preto, São Paulo. Fone (016) 633-1190, Fax (016) 633-3271. 


\section{CRIANÇAS E ADOLESCENTES EM SITUAÇÃO DE RUA}

Nas últimas décadas, a sociedade brasileira tem vivenciado um agravamento de sua situação social, resultando no aumento do número de famílias passando por dificuldades sociais e econômicas para cuidar de seus filhos que acabam evadindo das escolas, indo para as ruas lutar pela sobrevivência própria e de sua família. Esse fato fica mais grave quando o associamos a fenômenos como a explosão da violência urbana, a exploração do menor no mercado de trabalho, o extermínio de crianças, a crescente disccminação da AIDS, entre outros.

Segundo a Fundação Instituto Brasileiro de Geografia e Estatística - FIBGE (BRASIL, 1992), cerca de 4 milhões de crianças brasileiras não frequentam a escola. Um estudo amostral publicado pela Fundação Sistema Estadual de Análise de Dados (SEADE, 1993), aponta que na região metropolitana de São Paulo, 71\% das crianças com até 6 anos não freqüentam creches e pré-escolas. Mostra também que entre as crianças e adolescentes que estão fora da escola, $10 \%$ têm entre 7 e 10 anos, 22\% entre 11 e 14 e $68 \%$ entre 15 e 17 anos. Entre eles, a grande maioria, 90\%, abandonou a escola e cerca de $10 \%$ nunca a freqüentou. Os motivos alegados são trabalho, 32\%, falta de interesse $34 \%$ e outros motivos não especificados pelo estudo $34 \%$.

$\mathrm{Na}$ cidade em que foi desenvolvida esta pesquisa, o número de crianças fora da escola ainda era estimado a partir do senso demográfico de 1980 e os valores percentuais existentes eram semelhantes aos que FERRIANI (1992), apontou para o município em 1987, isto é, 67.830 crianças estavam matriculadas nas escolas de primeiro grau da rede pública estadual e municipal, correspondendo a 93,28\% da população na faixa de 7 a 14 anos. Percebe-se o baixo número de crianças matriculadas nas escolas, mas não podemos desconsiderar os altos indices de reprovação e evasão que respectivamente giram em torno de 7 a $10 \%$ para a $8^{\mathrm{a}}$ série do primeiro grau.

Essa situação aliada a outros fatores socioeconômicos contribui para o fato de um maior número de meninos e meninas procurarem as ruas como alternativa de sobrevivência e, na maioria das vezes serem exploradas pelos adultos enquanto mão de obra para pequenos serviços como; engraxar sapatos, vigiar carros, limpar párabrisas de automóveis nos semáforos, vender doces e frutas, até o envolvimento com roubos, latrocínios, tráfico e uso de drogas.

Diariamente recebemos informações que nos permitem afirmar que a realidade dessas crian- ças corresponde à de milhares de crianças brasileiras a qual favorece seu envolvimento num emaranhado de situações do universo da rua que as coloca numa situação de suscetibilidade à violação de seus direitos ante a violência do meio, levando-as também, a matar ou morrer pelos grupos de extermínio.

Diante de tal problemática e da infinidade de possibilidades de estudos sobre a temática, optamos por nos restringir, enquanto objeto de estudo, às percepções dos atores sociais que planejam e/ou coordenam programas voltados às crianças e aos adolescentes em situação de rua na cidade de Ribeirão Preto.

Sua realização justifica-se na medida que se constitui numa primeira aproximação ao tema da criança e adolescente em situação de rua pela enfermagem, considerando que não verificamos produção científica nessa área focalizando a questão no levantamento bibliográfico realizado em três bases de dados de literatura em saúde e em enfermagem (Index Latino Americano em Saúde - LILACS, MEDLINE e Catálogos do Conselho de Pesquisa em Enfermagem da Associação Brasileira de Enfermagem CEPEN), para o período compreendido entre 1982 e 1992.

Traçamos como objetivo deste trabalho conhecer e analisar as percepções dos atores sociais envolvidos no planejamento e/ou coordenação de programas de atenção à criança e ao adolescente em situação de rua na cidade de Ribeirão Preto (SP), com vistas a subsidiar a compreensão pelos profissionais de enfermagem acerca destes meninos e meninas. Mais especificamente pretendemos: (a) identificar os programas municipais e não governamentais de atenção a esse grupo; (b) identificar o significado de crianças em situação de rua para os coordenadores dos programas; e (c) identificar o significado desses programas para seus coordenadores.

Estes objetivos foram estabelecidos a partir dos pressupostos de que, no município de Ribeirão Preto, os programas de atenção aos meninos e meninas em situação de rua ocorrem de maneira isolada e fragmentada, que a ação conjunta entre instituições oficiais do município e não govemamentais, articula-se por iniciativa dos profissionais envolvidos nos programas, sem haver, entretanto, uma integração formal; que o profissional enfermeiro aparece de maneira pouco efetiva no planejamento e execução dos programas; e que, para a criança em situação de rua, o atendimento à saúde tem caráter emergencial, inexis-tindo um acompanhamento de seu crescimento e desenvolvimento de maneira sistemática e planejada. 


\section{METODOLOGIA}

O desenvolvimento deste trabalho foi orientado por um referencial qualitativo e por mostrar-se mais adequado ao alcance de nossos objetivos, optamos pela Pesquisa Estratégica. Este tipo de pesquisa é descrito por MINAYO (1993, p.26) de acordo com a definição de Bulmer como aquela que "baseia-se nas teorias das ciências sociais, mas orienta-se para problemas que surgem na sociedade, ainda que não preveja soluções práticas para esses problemas. Ela tem a finalidade de lançar luz sobre determinados aspectos da realidade. Seus instrumentos são os da pesquisa básica tanto em termos teóricos como metodológicos, mas sua finalidade é a ação. Essa modalidade seria a mais apropriada para o conhecimento e avaliação de Políticas, e segundo nosso ponto de vista, particularmente adequado para as investigações sobre Saúde”.

Propomos a utilização da pesquisa estratégica para descrever, revelar e aprofundar a análise de determinados aspectos da questão da criança e do adolescente em situação de rua na cidade de Ribeirão Preto, interior de São Paulo. Trabalhamos com as falas dos atores sociais que planejavam ou coordenavam a execução dos programas oficiais e não governamentais existentes no município para atender a este grupo, buscando compreender seu ponto de vista sobre o seu trabalho. Utilizamos também, como fonte de material para análise, documentos oficiais que versavam sobre os programas desenvolvidos no municipio assim como nossas observações de campo.

Determinamos como nosso campo de estudo a cidade de Ribeirão Preto como um todo, uma vez que estávamos desenvolvendo questões inerentes à criança e ao adolescente em situação de rua da cidade. Em linhas gerais o município possui aspectos que o caracterizam como um dos mais prósperos e ricos do interior paulista, mas não podemos deixar de considerar seus traços marcantes de subdesenvolvimento, pobreza e miséria.

Para a Secretaria Municipal do Bem-Estar Social existe na cidade um contingente estimado em 10.000 pessoas vivendo em condições precárias, praticamente em miséria absoluta, o que se reflete, entre outras coisas, em um número significativo de crianças que abandonam suas casas, escolas e perambulam pelas ruas da cidade em busca de alternativas para sua sobrevivência ou de seus familiares.

Observamos ao longo do trabalho de campo desta pesquisa que cerca de 20 crianças/adolescentes que viviam pela cidade exclusivamente na rua freqüentavam locais onde pudessem ter al- guma refeição e pernoitar. Outras tantas, permaneciam pelas ruas desenvolvendo algum tipo de atividade, porém mantinham vínculos familiares, freqüentavam escolas e estavam ali para ganhar algum dinheiro para ajudar em casa.

A Prefeitura Municipal através da Secretaria Municipal do Bem-Estar Social, o Poder Judiciário (Vara da Infancia e da Juventude) e o Ministério Público (Curadoria da Infância e Juventude), organizaram-se com vistas a encaminhar soluções de atendimento à criança e ao adolescente, priorizando intervenções em áreas defasadas aonde inexistia atendimento. Foi criado, em 1992, o Projeto Centro de Referência da Criança e do Adolescente (RIBEIRÃO PRETO, 1992), englobando quatro programas desenvolvidos pela Secretaria Municipal do Bem-Estar Social e dentre os objetivos de cada um destacamos:

Centro de Atendimento Básico: centralizar a demanda existente no município facilitando o diagnóstico da realidade social e os encaminhamentos; atender individualmente à situações-problema, agilizando as providências necessárias; engajar gradativamente crianças e adolescentes em diferentes programas comunitários possibilitando a participação solidária e responsável dos recursos existentes.

Casa - Abrigo: abrigar provisoriamente crianças e adolescentes em situação de risco pessoal e/ou social, impossibilitadas de retorno imediato ao grupo familiar; propiciar o atendimento às necessidades básicas da criança e do adolescente, integrar a criança e o adolescente em atividades sócio-educativas e de geração de renda; favorecer sua participação em rotina estruturada, oportunizando-lhe vivências diferenciadas, de modo a subsidiar futuras opções.

Pedagogia de Rua: abordar, no local onde se encontram, crianças e adolescentes, visando conhecer suas realidades e propor-lhes alternativas de modo a favorecer suas escolhas para sair da rua; favorecer a vivência de situações estruturadas e de vínculo através da abordagem procedida; promover momentos de reflexão, discutindo a realidade da rua, o resgate da condição social e reconstrução da história individual dessas crianças e adolescentes, engajar as famílias no processo sócio-educativo, tornando-as copartícipes do mesmo.

Centro Sócio-Pedagógico e de Iniciação Profissional: atuar como retaguarda efetiva do Programa "Pedagogia de Rua", dando continuidade e legitimidade ao mesmo; propiciar, através de uma dinâmica de funcionamento, condições a estas crianças e adolescentes, de organização de suas vidas, resgatando seus valores, sua autoestima e suas habilidades; integrar a criança 
e o adolescente em atividades sócio-educativas e de geração de renda; favorecer sua participação em rotina estruturada, oportunizando-lhe vivências diferenciadas, de modo a subsidiar futuras opções.

O Projeto como um todo previa um sistema de atendimento, que se caracterizava pela continuidade, articulação e oferecimento de retaguarda que fossem efetivas para a população alvo. Esse sistema de atendimento não era estanque e, desta forma, deveria dinamicamente assegurar a coesão entre os diferentes programas.

Além desses programas desenvolvidos pela Secretaria do Bem-Estar Social, Instituições não governamentais complementavam o atendimento à criança e ao adolescente, em especial àqueles que estavam nas ruas. Dentre outras de menor porte destacavam-se a Casa das Mangueiras, desenvolvendo trabalho profissionalizante com meninos que já voltaram para casa e a "Casa Aberta ou de Convivência” da Pastoral do Menor, consistindo de uma casa alugada no centro da cidade onde era oferecida, aos meninos e meninas duas refeições diárias, banho, atividades recreacionais supervisionadas entre outras. O propósito era oferecer um caminho para aqueles que queriam sair da rua, no entanto, sem se caracterizar como um lar substituto.

Vale salientar que o conjunto de programas que consideramos neste estudo foram sendo reestruturados, de acordo com as diretrizes administrativas, políticas e sociais do município bem como das organizações não governamentais, desde o período em que coletamos os dados, isto é, nos anos de 1993 e 1994. Nesse sentido, alguns programas citados não mais são desenvolvidos e, em outros, as propostas de trabalho sofreram alterações importantes. Porém não enfocamos, neste estudo, as características dos movimentos dos programas mas os apresentamos na forma como se dispunham naquele momento.

Em concordância ao ECA, foi instalado em Ribeirão Preto no ano de 1992, o Conselho Municipal de Defesa dos Direitos da Criança e do Adolescente, sendo uma de suas competências formular a política municipal de direitos da criança e do adolescente após amplo debate com a sociedade; porém o conselho não atuava diretamente com a criança e o adolescente.

No que se referia ao atendimento à saúde, dessa população, estava implícita a universalização da assistência, não havendo, pelo menos no discurso, nenhum tipo de diferenciação no atendimento.

Para coletarmos os dados desse estudo, optamos por utilizar em campo de trabalho as técnicas da observação livre e entrevistas semi- estruturadas, planejadas e executadas pelo próprio pesquisador. Estas técnicas têm destaque especial quando se trabalha em uma pesquisa de abordagem qualitativa porque se constituem instrumento facilitador nas relações entre o pesquisador e o fenômeno por ele estudado (MINAYO, 1993 e 1993a; HAGUETTE, 1992).

Primeiramente levantamos e examinamos os documentos oficiais junto às Secretarias Municipais do Bem-Estar Social e de Saúde. Posteriormente, realizamos nossas observações na “Casa Aberta ou de Convivência” da Pastoral do Menor, que reunia condições adequadas e necessárias para observarmos como se desenvolvia parte do cotidiano daqueles meninos e meninas em situação de rua inserida num dos programas assistenciais. Este processo estendeu-se por três semanas no mês de junho de 93, por cerca de 90 minutos por dia entre 12:30 h. e 14:00 h.. Todo o material foi devidamente registrado em um "Diário de Campo”.

Oportunamente trabalhamos com as falas dos coordenadores dos programas, procurando realizar uma quantidade suficiente de entrevistas para garantir a repetição das informações que repetissem o conjunto de suas experiências e significados acerca do trabalho com meninas e meninos em situação de rua.

Foram sujeitos sociais desta pesquisa, cinco profissionais de nível superior envolvidos na elaboração/coordenação de cinco programas diferentes entre as instituições governamentais e não governamentais atuantes na cidade com atividades voltadas às crianças e aos adolescentes em situação de rua.

Todas as entrevistas foram gravadas com a permissão dos entrevistados e posteriormente transcritas dentro dos padrões compatíveis com o software “The Ethnograph - Version 3.0”, utilizado como recurso auxiliar no preparo das entrevistas para análise.

\section{ANALISE DOS DADOS}

Construímos a análise dos dados seguindo a proposta hermenêutica-dialética elaborada por MINAYO (1993), onde a fala dos atores sociais é situada em seu contexto para ser melhor compreendida. De acordo com GOMES (1994), as etapas operacionais da análise constituem-se na ordenação dos dados (transcrição de gravações, releitura do material, organização dos relatos e dos dados da observação); classificação dos dados (construída a partir dos questionamentos que fazemos sobre os dados baseados numa fundamentação teórica); análise final (articulação entre 
os dados e os reverenciais teóricos da pesquisa, respondendo às questões da pesquisa com base em seus objetivos).

Os atores entrevistados eram profissionais de diversas áreas como psicologia, terapia ocupacional, enfermagem e serviço social, com idades variando de 27 a 38 anos de idade e todos do sexo feminino. Com exceção da enfermeira, que na época da entrevista fazia apenas três meses que se envolvera na elaboração de um projeto de saúde para meninos e meninas em situação de rua, o restante desenvolvia alguma atividade com esse grupo no mínimo há cinco anos.

De maneira geral as respostas expressaram o pensamento crítico-analítico sobre a situação da criança e do adolescente em situação de rua em Ribeirão Preto, mas em determinados momentos, alguns entrevistados limitaram suas colocações abordando as questões de modo incompleto, sendo necessário, muitas vezes, estimularmos um aprofundamento em seu conteúdo. Em outros momentos observamos certa cautela nas respostas de forma a não se comprometerem, uma vez que se colocavam na posição de representantes de suas instituições de trabalho. Assim, após várias leituras das transcrições foi possível extrairmos as categorias que apresentaremos e discutiremos a seguir.

\section{A criança e o adolescente em situação de rua}

Em síntese os atores sociais compreendem as crianças e os adolescentes em situação de rua como outras quaisquer que atravessam suas respectivas fases de crescimento e desenvolvimento mas que, por fatores distintos e diversos como a pobreza e problemas de relacionamento familiar, têm nas ruas uma experiência de vida onde acabam se expondo aos riscos pessoais e sociais característicos do meio, como podemos perceber através de suas falas:

"A criança de rua é o segmento da população mais prejudicado em função da situação socioeconômica, abandono e inexistência de políticas públicas do país."

"Á criança que está em situação de rua é uma criança como outra qualquer, mas está sendo privada de alguns direitos. Mas é uma criança que tem vontade de brincar, que tem sensibilidade, que chora, que ri.."

"E uma criança mesmo. Eu a vejo como uma criança.

Acima de qualquer coisa ela é uma criança."
O discurso oficial não apresenta explicitamente sua concepção à respeito daqueles a quem pretende atender, ou seja, não traça um perfil sobre a criança e o adolescente que vivem em situação de rua em Ribeirão Preto. COSTA et al. (1990) descrevem a possibilidade de diferentes percepções sobre a criança. Por exemplo, a do sociólogo que a concebe como produto do processo desorganizado de urbanização, cujos efeitos desagregadores sobre a estrutura familiar e comunitária resultam em sua condição. Para o senso comum, ora é percebida como pedinte e maltratada, objeto de pena e caridade, ora como uma ameaça social devendo ser trancafiada em reformatórios. Essa discussão nos leva a pensar que a compreensão sobre a criança está ligada a fatores externos e inerentes ao meio em que ela vive, isto é, são produtos da sociedade.

Dessa maneira a criança e o adolescente devem ser percebidos como cidadãos desde antes do nascimento mesmo apresentando características de desenvolvimento distintas conforme a idade em que se encontram e, as ações de proteção à vida e à saúde devem compreendê-los em sua totalidade sem abandonar suas especificidades adotando como referência um conceito ampliado de saúde, entendido enquanto condições de vida que assegurem acesso aos serviços de saúde e à educação formal, trabalho, lazer, alimentação, habitação, no sentido de garantir à criança e ao adolescente seu crescimento e desenvolvimento normal (DALLARI \& KORLZAK, 1986; CDH, 1990; ABRINQ e cols., 1994).

Com relação ao aspecto da saúde, conforme constatamos em nossas observações, as crianças em situação de rua de Ribeirão Preto apresentam graves problemas, como o uso de drogas e álcool, tabagismo e infecção pelo HIV entre outras doenças, sendo portanto, necessário, junto a elas, um acompanhamento mais próximo através de um trabalho de educação em saúde, por exemplo.

Embora um dos atores sociais pertença à categoria profissional dos enfermeiros, este não trabalha diretamente com a criança e o adolescente em situação de rua. Nesse sentido apontamos a possibilidade de ampliação dos horizontes para a prática da enfermagem, pois o enfermeiro, sendo um profissional capacitado técnica e cientificamente para planejar, coordenar e executar ações de saúde, pode também fazê-las para este grupo. No entanto esta atuação deve estar livre de preconceitos, alicerçada numa visão abrangente sobre quem é essa criança e esse adolescente, os motivos que os levaram a permanecer pelas ruas.

Dessa maneira, conhecendo as características dessa população e tendo mais clara a dimensão do mundo dessas crianças e adolescentes cer- 
tamente prestará uma assistência efetiva, conferindo-lhes um melhor acompanhamento de saúde, educação em saúde na prevenção de doenças, uso de drogas e álcool e relacionamento, entre outras tantas formas de se garantir uma vida um pouco mais saudável. Segundo a fala da coordenadora de um dos programas:

"Na verdade seria muito bom ter alguém da área da saúde aqui para discutir com os meninos assuntos sobre

AIDS, uso de drogas “

Percebemos num primeiro momento nas observações de campo que para estes meninos e meninas em situação de rua, a saúde é sinônimo de não estar doente, restringindo-se ao físico, ao biológico. No entanto, devemos considerar que apesar da representação de saúde para estes meninos e meninas restringir-se à ausência de determinadas patologias, nas falas que captamos ao longo de nossas observações se refletem a qualidade de vida, tanto que especificam sobre a necessidade de se manter a casa limpa, a não utilização de drogas, trabalho, condições de habitação, antes de dizerem que conversa de saúde não é importante.

No que se refere ao atendimento à saúde observamos o discurso de integração de diversos setores para o atendimento global a esses meninos e meninas contrapondo-se a uma prática de atendimento de caráter estritamente emergencial, sem nenhum trabalho preventivo e acompanhamento de seu crescimento e desenvolvimento de maneira planejada.

Segundo PRADO \& GOMES (1993), conflitos familiares, e, principalmente, as condições de pobreza são fatores responsáveis pela utilização da rua, pelas crianças e adolescentes, como fonte geradora de renda, quer por meios socialmente aceitos ou não. Das entrevistas realizadas, destacamos os depoimentos onde estes pontos são abordados como causa da procura das crianças pela rua:

"Á atual crise econômica brasileira está favorecendo o aumento do número dessas crianças na rua. "

"É o retrato perfeito da segregarão. da exclusão social.

Estão nas ruas por necessidade de sobrevivência. Na maioria dos casos buscam nas suas respostas para as necessidades de sobrevivência."

"Á desestrutura familiar, a pobreza bastante acentuada, ou por não se encontrar dentro de escolas, enfim, existiu um fato que

\section{levou essa criança a permanecer na rua e fazer da rua \\ a sua moradia”}

O fato da criança não se encontrar freqüentando regularmente a escola, é apontado como um dos fatores que favorece a criança permanecer nas ruas. PRADO \& GOMES (1993) observam a esse respeito que "a inadequação da escola em promover um processo educativo para a infância pobre articulada à própria razão prática que determina os interesses de sobrevivência cotidiana da população de baixa renda”, também contribui para a criação de barreiras entre a criança e a escola. Ribeirão Preto possui uma estrutura montada para o ensino básico inclusive contando com um Programa de Atenção Primária em Saúde Escolar PROASE já descrito por FERRIANI (1992 e 1994) e, ainda assim, é possível encontrarmos dezenas de crianças pelas ruas e fora da escola.

Mas enfim, o fato das crianças e adolescentes estarem vivendo nas ruas é a manifestação mais explícita e perversa da incompetência da sociedade brasileira em promover desenvolvimento econômico, distribuição de renda, igualdade de oportunidades, políticas públicas básicas efetivas e direitos humanos garantidos (SOUZA NETO, 1993; ABRINQ e cols.,1994).

Nos depoimentos da maioria dos atores sociais está implícito um aspecto que consideramos relevante, relacionado aos termos que atribuem às crianças e adolescentes em situacão de rua, onde se reflete a tentativa de afastá-los dos estereótipos e estigmas previamente determinados pela sociedade como por exemplo menores, pivetes, trombadinhas, delinqüentes, menores carentes, moleques de rua, marginais, os quais reforçam a omissão, discriminação e descaso do Estado e sociedade:

"São crianças em situação de risco e de abandono."

"Entre aspas meninos de rua, sempre (...). Meninas de rua... não sei se o termo está correto. Acho que a gente vai ter que começar a falar de outro jeito porque a rua não pariu ninguém."

"Hoje a gente estuda o termo criança de rua e analisamos que não existe criança de rua, mas a que está em situação de rua."

MINAYO (1993a) e DALLARI \& KORCZAK (1986) apontam a inadequação dessas denominações para expressar a realidade dessas crianças e adolescentes e que estes termos estão semanticamente carregados de preconceitos que atravessam a formação social brasileira ao longo de sua história. 
A leitura das entrevistas de um modo geral, permite-nos apontar que a criança e o adolescente em situação de rua podem ser denominados de excluídos, marginalizados, abandonados, por tentarem transpor suas dificuldades e precárias condições de vida, buscando, no espaço da rua, alternativas muitas vezes desesperadas para garantir no mínimo o próprio sustento.

Portanto, estes pontos vêm confirmar nossa percepção sobre a criança e o adolescente que estão na rua utilizando-a como estratégia para garantir sua sobrevivência e/ou de seus familiares, mas é importante não nos prendermos ao estereótipo de criança de rua como infratora e abandonada, atribuindo-lhe a culpa exclusiva por essa situação, por constituírem-se conceitos simplistas e limitados que não reconhecem o direito de serem tratados como pessoas.

\section{Significaclo dos programas de atenção à criança e ao adolescente em situação de rua para os atores sociais}

De acordo com a síntese dos depoimentos dos atores sociais, pudemos perceber que em Ribeirão Preto não existe uma política formal de atendimento direcionada a este grupo, mas apenas tentativas através de programas específicos.

"Não existe muita experiência. A gente está buscando fora.

Concretamente ainda está começando a pensar no atendimento."

"Falta em Ribeirão Preto, atendimento direto à criança que está na rua."

"Não existe uma política formal. existem tentativas de atendimento.

Dentro do que podemos oferecer existe um mínimo."

Segundo os depoimentos dos atores sociais, as políticas de ação social são implantadas porque as políticas públicas básicas falharam. Os entrevistados têm consciência de que isso implica em muito trabalho a ser realizado principalmente no sentido de criar condições para as crianças e os adolescentes deixarem a rua e atendê-los integralmente:

"Existe muito trabalho para conseguirmos atendê-los de modo integral."

"As políticas de ação social são implementadas e tentadas quando as outras falharam. A gente vem pra tapar o grande buraco. Eu falo da política de educação. saúde, habitação, abastecimento, saneamento básico, e, não é possível a gente propor uma ação que tape esses buracos."

"Para que o trabalho creş̧a temos que estar implementando ações que chamem de verdade e não temporariamente a meninada."

Essa visão confirma-se na literatura onde detectamos que as políticas sociais brasileiras das últimas décadas foram elaboradas visando cobrir os fracassos constantes das políticas de desenvolvimento e garantir o controle social.

SOUZA NETO (1993) e COSTA et al. (1990) apontam que esse caráter das políticas sociais manifesta-se quando cresce o número de analfabetos e cria-se o MOBRAL (Movimento Brasileiro de Alfabetização), quando as crianças passam fome e são distribuídas cestas básicas e leite e, quando são criadas instituições para receber crianças que estão nas ruas.

As dificuldades que se apresentam no todo das entrevistas são muitas, mas destacam-se aquelas que apontam a falta de apoio da sociedade em geral na busca de alternativas para o atendimento, sendo que muitas vezes, determinados segmentos da sociedade, colocam empecilhos que impedem a ação dos coordenadores no desenvolvimento dos programas:

"O maior problema e o mais

dificil de enfrentar é a rejeição da

sociedade pela criança que está nas ruas. Enquanto não se

reverter isso, pode-se instalar mil

trabalhos aqui em Ribeirão Preto no sentido de resgatar esta criança que não vai conseguir.

(...) As pessoas colocam uma

resistência muito grande e tentam resolver o problema delas...

No fundo você vê que não estão preocupadas em resolver o problema que a criança está vivendo. “

Constatamos nas observações na Casa de Convivência que, por estar localizada em área residencial do centro da cidade, provocava um certo incômodo na vizinhança, que não aceitava a sua existência nas imediações, procurando inclusive meios legais que determinassem seu fechamento compulsório. Em meio a outros fatores como dificuldades em renovar o contrato de aluguel, a Casa encerrou suas atividades naquele local, por tempo indeterminado, no período em que realizávamos nosso trabalho de campo. Suas atividades passaram a ser desenvolvidas parcialmente pela Casa Dormitório, que se localizava em um 
bairro distante cerca de quatro quilômetros do centro da cidade.

Quadro semelhante percebemos ao longo da história, quando a criança era depositada nas Rodas dos Expostos, encaminhadas aos asilos e às amas, ou seja, quando os filhos bastardos eram afastados do convívio familiar e social (DONZELOT, 1986, DEL PRIORE, 1991; MARCILIO, 1993; MEDEIROS, 1995). Apesar de contextos distintos, momentos históricos diferentes, as famílias da atualidade ainda abandonam seus filhos, em grande parte por uma questão de sobrevivência.

Para COSTA et al. ( 1990), a reação à ameaça, que supostamente a criança representa, funde-se com o estereótipo da periculosidade fazendo com que a simples presença de determinadas crianças e jovens, com certas características, em certos lugares, justifique os atos repressivos adotados.

Outra dificuldade ressaltada nas falas dos atores sociais, diz respeito à integração entre as secretarias municipais e organizações não governamentais no desenvolvimento dos programas voltados para o grupo em questão:

"A grande dificuldade é trabalhar

de forma integrada e articulada nos níveis Federal. Estadual e

Municipal, com clara definição de competências, de forma mais clara, procurando integrar também a sociedade civil, as comunidades locais, como um exercício da cidadania. Mas toda vez que se tentou atender junto, não deu, quebrou, estourou, arrebentou!..."

Muito embora o Projeto "Centro de Referência da Criança e do Adolescente" apresente explicitamente a necessidade de integração não só com outros programas, observamos que na prática isto acontece, efetivamente, através de acordos verbais entre os interessados. Possivelmente isto se dá porque não foram estabelecidos critérios neste Projeto prevendo essa ponte entre as instituições municipais e não-governamentais prestadoras de atendimento.

Este quadro vem confirmar os pressupostos de que a ação conjunta entre as instituições oficiais do município e as não governamentais, articula-se por iniciativa dos profissionais envolvidos nos programas, sem haver, entretanto, uma integração devidamente planejada e que também, no município de Ribeirão Preto, os programas de atenção aos meninos e meninas em situação de rua ocorrem de maneira isolada e fragmentada.
Chamou-nos a atenção o fato de que em apenas uma entrevista houve alusão ao envolvimento dos meninos e meninas com o tráfico de drogas o qual foi apontado como uma das grandes dificuldades que se tem enfrentado no decorrer dos programas:

“(...) muitas crianças foram

abordadas pelos traficantes, pelos

receptadores, que acabavam

ofèrecendo um pouco mais do que

a Casa Dormitório. por que eles

queriam que elas continuassem

dormindo na rua porque é de

noite que a coisa pega, que se faz os arrombamentos.

Principalmente os menores, no tamanho, pararam de dormir na Casa."

MINAYO (1993a) ressalta o envolvimento com o narcotráfico e a utilização das crianças e dos adolescentes como parceiros precoces da violência e delinqüência dos adultos, representando, portanto, um problema bastante delicado que exige providências urgentes.

O Relatório Anual do Departamento Estadual de Investigações sobre Narcóticos DENARC (1993) aponta, para o ano de 1993, que no Estado de São Paulo, 91\% dos dependentes de drogas são do sexo masculino e $9 \%$ do sexo feminino. A droga de maior uso é o crack, seguido da cocaína, maconha, poliuso (preponderantemente crack), álcool e cola de sapateiro que corresponde a $1 \%$ do uso. Quanto à idade, a faixa etária de 0 a 15 anos corresponde a $7 \%$ e de 16 a 18 anos a $20 \%$ do total dos usuários do sexo masculino. Para as mulheres, 21\% está na faixa etária de 0 a 15 anos e $24 \%$ entre 16 e 18 anos. Para os traficantes, a faixa etária predominante é de 21 a 29 anos, sendo $20 \%$ mulheres e $80 \%$ homens.

É válido lembrar que no discurso oficial que temos como suporte de análise (RIBEIRÃO PRETO, 1992), não estão previstas ações, sejam preventivas ou terapêuticas, voltadas para crianças e adolescentes em situação de rua que fazem uso habitual de qualquer tipo de droga. No entanto, o Conselho Municipal de Defesa dos Direitos da Criança e do Adolescente e a Secretaria Municipal de Saúde, entre outros, adotam estratégias de atendimento à criança e ao adolescente através de ações preventivas junto à comunidade em geral que ainda não faz uso de drogas (como os escolares por exemplo), assim como atividades isoladas aos usuários dependentes.

Na maioria das entrevistas os atores sociais não apontaram nenhuma facilidade que encontraram para o desenvolvimento dos programas, mas eventualmente aparecia como tal o trabalho em 
parceria entre o Poder Público e a sociedade civil representados pela Secretaria do Bem-Estar Social e Pastoral do Menor.

Pelo que pudemos perceber, o significado dos programas de atendimento à criança e ao adolescente em situação de rua, sob o ponto de vista de seus coordenadores, nos indica que enfrentam dificuldades que, em primeira análise, parecem intransponíveis porque envolvem problemas em níveis mais abrangentes tais como, o preconceito e o descaso da sociedade, a falta de vontade política, os quais refletem-se em níveis mais específicos em termos de condições mínimas que proporcionem suporte ao desenvolvimento dos programas.

\section{CONCLUSÃO}

Consideramos que o processo de elaboração desta pesquisa permitiu-nos uma primeira aproximação sobre a temática da criança e do adolescente em situação de rua pela enfermagem, merecendo estudos posteriores que aprofundem outros aspectos que neste momento não foi possível trazermos para discussão.

$\mathrm{O}$ que apresentamos antes de tudo mostra-

\section{BIBLIOGRAFIA}

ABRINQ/CBMM/UNICEF/OFICINA DE IDÉIAS. 10 Medidas básicas para a infância brasileira. São Paulo, Fundação ABRINQ para os Direitos da Criança, 1994.

BRASIL. Secretaria de Planejamento e Coordenação da Presidência da República / Fundação Instituto Brasileiro de Geografia e Estatística. Crianças \& Adolescentes: indicadores Sociais, v. IV. Rio de Janeiro, 1992.

CDH - CENTRO DE ESTUDOS DO CRESCIMENTO E DESENVOLVIMENTO DO SER HUMANO. Estatuto da Criança e do Adolescente: planilha para operacionalização. Convênio CDH/CBIA/SP. São Paulo, 1992.

COSTA, A. C. G. et al. Brasil. Criança. Urgente. A Lei 8069/90. São Paulo, Columbus Cultural Editora, 1990.

DALLARI, D. A.; KORCZAK, J. O direito da criança ao respeito. São Paulo, Summus Editorial, 1986.

DEL PRIORE, M. org. História da criança no Brasil. São Paulo, Contexto, 1991.

DENARC - DEPARTAMENTO ESTADUAL DE INVESTIGAÇÕES SOBRE NARCÓTICOS. Relatório Anual - 1993. São Paulo, 1993. [mimeo]. se como um caminho, um instrumento ou ainda um exercício que possibilitou emergir aspectos que trouxemos em discussão na área da enfermagem.

Nesse sentido apresentamos como recomendação para que as propostas de mudanças viabilizem-se no campo do atendimento, alguns pontos básicos nos quais devem-se apoiar, apresentados por COSTA et al. (1990, p 93), isto é, "vontade política manifesta dos governantes; capacidade de articulação interinstitucional dos setores em presença; elaboração conjunta de proposta de trabalho integrado; capacitação das pessoas para aderir, compreender e operar o modelo de atendimento; recursos físicos capazes de garantir a base logística do processo; estabelecimento de mecanismos permanentes de acompanhamento e avaliação.”

Além disso, compreendendo a complexidade da questão, concluímos que numa fase anterior ao planejamento de quaisquer programas de atenção às crianças e aos adolescentes que vivem em situação de rua, neste caso, em Ribeirão Preto, há necessidade de conhecermos seu perfil e suas necessidades a partir delas mesmas, de forma a garantir o rmmmo de resolutividade de qualquer projeto.

DONZELOT, J. A polícia das famílias. Rio de Janeiro, Graal,1986.

FERRIANI, M.G. C. A inserção do enfermeiro na saúde escolar. São Paulo, EDUSP, 1992.

FERRIANI, M.G. C. Percepções dos atores sociais que utilizam o programa de assistência primária em saúde escolar (PROASE) no Município de Ribeirão Preto: análise critica. Ribeirão Preto, 1994. [Tese de Livre Docência Escola de Enfermagem de Ribeirão Preto/ USP].

GOMES, R. AAnálise de dados em pesquisa qualitativa. In: MINAYO, M. C. S. et al. Pesquisa social: teoria, método e criatividade. Petrópolis, Vozes, 1994.

HAGUETTE, M. T. F. Medotologias qualitativas na sociologia. $38^{a}$ ed. Petrópolis, Rio de Janeiro, Vozes,1992.

MARCILIO, M. L. org. Família, mulher, sexualidade e igreja na história do Brasil. São Paulo, Edições Loyola, 1993.

MEDEIROS, M. Percepções dos atares sociais que coordenam programas de atenção às crianças e aos adolescentes em situação de rua no municipio de Ribeirão Preto (SP). Ribeirão Preto, 1995. [Dissertação de Mestrado. Escola de Enfermagem de Ribeirão Preto/USP]. 
MINAYO, M. C. S. O desafio do conhecimento: pesquisa qualitativa em saúde. São Paulo/Rio de Janeiro, HUCITEC - ABRASCO, 1993.

MINAYO, M. C. S. org. O limite da exclusão social: meninos e meninas de rua no Brasil. São Paulo/Rio de Janeiro, HUCITEC/ABRASCO, 1993a.

PRADO A. A.; GOMES, R. A rua: institucionalização da exclusão social. In: O limite da exclusão social: meninos e meninas de rua no Brasil. M.C.S. MINAYO et al., São Paulo/ Rio de Janeiro, HUCITEC/ABRASCO, 1993.
RIBEIRÃO PRETO. Prefeitura Municipal. Projeto centro de referência da criança e do Adolescente de Ribeirão Preto. Ribeirão Preto, 1992. [mimeo]

SEADE - FUNDAÇÃO SISTEMA ESTADUAL DE ANÁLISE DE DADOS. Crianças e adolescentes: pesquisa de condições de vida na região metropolitana de São Paulo. Análises especiais - 1. São Paulo, 1993.

SOUZA NETO, á. C. S. De menor a cidadão: filantropia, genocídio políticas assistenciais. São Paulo, Nuestra America Editoraas, 1993.

recebido: 10/10/96 aprovado: 18/11/96 